Editorials

\title{
Protecting Crop Species from Biotic and Abiotic Constraints in the Era of Global Change: Are we ready for this Challenge?
}

\author{
Marco Landi and Giovanni Benelli \\ Department of Agriculture, Food and Environment, University of Pisa, Pisa, Italy
}

Reliable and affordable supply of food is of crucial importance to the progress and stability of human societies. During the last century, we have assisted to an extraordinary increase of crop yields, especially for the most widespread and consumed crop species, such as rice, wheat, corn and soybean. The Broadbalk experiment, one of the oldest continuous agronomic experiments in the world, have showed how half of the increase of crop productivity is mainly due to the improvements introduced through plant breeding and half through to agronomical practices, although both are dependent on each other (Rasmussen et al., 1998). The development of a huge numbers of scientific plant breeding programs has been of vital relevance in improving crop varieties and productivity. In addition, collection and spread of improved germplasm around the world have ensured that all breeders could quickly benefit from the advances obtained by others. On the other side, based on Lawes and Gilbert's work in the previous century, the main advances in agronomy consisted on the continued use of fertilizers, the true value of which could only be realized in the presence of suitable varieties and in the absence (or under controlled pressure) of competition from weeds, pest and diseases. Therefore, crop protection became crucial and it was achieved by the improvements of the agrochemical industry, which has developed sophisticated, hightargeting and more efficient agrochemicals. Taken together, the use of new high-yield varieties in association with chemical fertilizers and agrochemicals, controlled water-supply (irrigation), and new methods of cultivation, including mechanization, are commonly identified under the term "Green Revolution" which was conied between ' 30 and ' 60 and was responsible in some cases for doubling (or even triplicating) the agricultural production for many crops species, in particular cereals.

The incremented crop productivity has brought many social gains, such as reducing the malnutrition, lowering food price, increasing food security. Moreover, since the economic sustainability is the most important factor for the adoption of a crop for farmers (Sgroi et al., 2014; Testa et al., 2015), the increased crop productivity occurred in the last decades, has determined a positive impact on the development of several rural areas.
The increase of crop yield, has caused, on the other side, large changes in rural societies due to the migration of population from the countryside (caused by the decrease of manpower needs) to towns and cities where the industrialization offered more opportunities. The better living conditions lead to the highest increment of word population that has ever been documented: from $2.5 \mathrm{~b}$ people to $5.2 \mathrm{~b}$ in 40 years (1950-1990; UNR, 2004). Nowadays, word population is predicted to increase from $7.4 \mathrm{~b}$ people (May, 2016), to $8.4 \mathrm{~b}$ in 2030 and $9.5 \mathrm{~b}$ in 2050 (U.S Census Bureau). In addition, people rise out of poverty, higher living standards, such as greater meat consumption, and personal mobility will increase even more the demand on food production (and quality), animal feed, fiber, and fuels. Thus feeding, clothing and fueling a more densely populated planet is probably the key challenge of our century.

Industrialization and anthropic activities have also imposed profound alterations to the environment and, decade after decade, have contributed to alter dramatically the life conditions on Earth leading to the so called "Global Change" (also referred as "Global Warming" or "Climate Change"), phenomenon from which we are actually trying to run for cover. Based on several reports produced by the Intergovernmental Panel on Climate Change, it emerges as the most hazardous effects of Global Change, such as rising temperatures and heat waves, prolonged periods of drought, and incremented levels of pollutants in all the compartments of biosphere can cause more frequent and severe fluctuations in crop productivity, but also can seriously threaten the availability of arable land; for example increasing the amplitude of soil/water salinization or soil erosion. The total surface of arable soil is also undermined by the constant requirement of lands for human activities that, beyond the direct effect of overbuilding, in many cases also increase the pollution of surrounding areas, for example through the release of heavy metals, hydrocarbons, xenobiotics or other pollutants in soil, water, and/or in the atmosphere. Global Change also influences the ecology of weeds, pests and disease, with possible implications for crop protection and pesticide use. 
The ability of science to make predictions on the impact of Global Change on ecosystem interactions is limited because models that include multiple interactive effects of Global Change are still relatively rare and the comprehension of results obtained from model systems results quite complicated. For this reason, despite the scientific community concords on the dramatic impact of Global Change on crop productivity, predictions may have sometimes-different facets depending on the information source. Some researchers reported however that in the time span 1981-2001, changes in precipitation and increased temperatures have already induced annual losses of wheat, maize and barley production of about 40 million tons per year (Lobell and Field, 2007). Thus, beyond future prediction(s) of Global Change effect, humanity is still experiencing the effects this phenomenon for at least three decades.

It is evident that in a near future a key challenge for humanity is to increase the productivity of crop species while decreasing water supply, the use of fossil fuels, chemical fertilizer, pesticides (and more in general agrochemicals), and other negative environmental inputs. On the other side, less clear is how agriculture's output can increase so substantially without significantly increasing its environmental footprint.

Plant physiology and biochemistry have developed as powerful disciplines during the $20^{\text {th }}$ century, but only in a few cases they have led to relevant crop improvement, and in any case, nothing as compared to the amazing gains on crop productivity obtained through the classical genetic breeding from 1930 to 1960 . This is likely because the links between the biochemistry and genetics of the processes described were not established, but rather high-yield genotypes were selected only for this desired feature lacking to explore the reason on the bases of this gain. The situation has changed after the discovery of the DNA structure by Watson and Crick (1953) and even more after '70, when the first positive results with transgenic plants were obtained. From that time onward, the ability to control one or few genes has also deepened the knowledge on the biochemical mechanisms underlying the genetic process that has been modified. This new approach, associated with the rapid development of "omic" sciences, has the potentiality to lead to significant advances either in crop yield, quality, and/or plant protection in a near future.

The future need for higher crop productivity must parallel with a reduction of agronomical inputs as in the past high-yield genotypes have been selected for their performances with high inputs, especially fertilizers and pesticides. Agricultural emissions from crop and livestock production grew from 4.7 billion tons of carbon dioxide equivalents $\left(\mathrm{CO}_{2} \mathrm{eq}\right)$ in 2001 to over 5.3 billion tons in 2011. In the same period, annual emissions from fertilizers increased by $37 \%$ and in 2011 the world total annual emissions from synthetic fertilizers averaged $725 \mathrm{Mt} \mathrm{CO}_{2}$ eq, about $14 \%$ of total emissions from agriculture in the same year (Tubiello et al., 2014). Advances in the basic knowledge of plant genetic, physiology and biochemistry should thereby be address to increase the efficiency of input utilization by plants in order to reduce the input level. Technological advances on instrumentations, such as precision farming tools (such as GPS tracking devices designed for farming), as well as agronomical practices (i.e. advanced organic farming, eco-friendly soil amendments) can also significant contribute to achieve this goal.

The extensive employ of synthetic pesticides against pests of agricultural and veterinary importance, especially in developing countries, lead to important concerns for human health and the environment (Desneux et al., 2007; Hemingway and Ranson, 2000; Naqqash et al., 2016). In this scenario, the need for effective and eco-friendly control tools has gained increasing attention in latest years (Benelli, 2015; 2016). Besides this, a further challenge for crop and livestock protection nowadays, is the improvement of the success of biological control programs, developing effective quarantine procedures and proper evaluation of the nontarget effects of biocontrol agents (Hajek et al., 2016).

Furthermore, chemoecological knowledge about pests and biocontrol agents may represent a valid help to improve integrated pest management strategies. Indeed, foraging kairomones exploited by carnivorous arthropods have been successfully tested as field lures to attract carnivores in damaged agricultural habitats. However, practical applications of foraging kairomones seem to be restricted by major concerns including carnivorous arthropod habituation, carnivorous arthropod time-wasting on victim-free crops, exploitation of host-borne cues by hyperparasitoids and lack of foraging kairomones specificity due to tritrophic interactions sharing a given habitat that use identical chemical signals, thus confounding speciesspecific biological control agents (Kaplan, 2012). Further research on new applications of physical and chemical signals exploited by carnivorous arthropods is urgently required. Physical and olfactory cues can be used to experience mass-reared predators and parasitoids, via sensitization or associative learning practices (Giunti et al., 2016). This could help to overcome critical steps in mass rearing of biocontrol organisms and improve beneficial performances of carnivorous arthropods in the field.

In view of the growing scientific interest on the effects of Global Changes factors on the relationship between plant-pest-environment, in this issue a collection of papers focused on this topic are presented. Beyond awareness of the deleterious impact of Global 
Change, factor which should lead humanity to a wiser use Earth's resources, we believe that only the in-depth comprehension of mechanisms adopted by crop species to endurance under stress (Landi et al., 2012; 2013; 2014; 2015; Pardossi et al., 2015; Penella et al., 2016; Tattini et al., 2014) associated with new eco-friendly methods to control crop pests and diseases may represent a way to contrast the effect of Global Change meanwhile we are attempting to increase crop productivity for supporting the needs of an increasingly crowded planet.

\section{References}

Benelli, G., 2015. Research in mosquito control: current challenges for a brighter future. Parasitol. Res, 114: 2801-2805.

Benelli, G., 2016. Plant-mediated biosynthesis of nanoparticles as an emerging tool against mosquitoes of medical and veterinary importance: A review. Parasitol. Res., 115: 23-34.

Desneux, N., A. Decourtye and J.M. Delpuech, 2007. The sublethal effects of pesticides on beneficial arthropods. Annu. Rev. Entomol., 52: 81-106.

Giunti, G., A. Canale, R.H. Messing, E. Donati and C. Stefanini et al., 2015. Parasitoid learning: Current knowledge and implications for biological control. Biol. Control., 90: 208-219.

Hemingway, J. and H. Ranson, 2000. Insecticide resistance in insect vectors of human disease. Annu. Rev. Entomol., 45: 371-391.

Hajek, A.E., B.P. Hurley, M. Kenis, J.R. Garnas and S.J. Bush et al., 2016. Exotic biological control agents: A solution or contribution to arthropod invasions? Biol. Invasions. DOI: $10.1007 / \mathrm{s} 10530-016-1075-8$

Kaplan, I., 2012. Attracting carnivorous arthropods with plant volatiles: The future of biocontrol or playing with fire? Biol. Control, 60: 77-89.

Landi, M., E. Degl'Innocenti, A. Pardossi and L. Guidi, 2012. Antioxidant and photosynthetic responses in plants under boron toxicity: A review. Am. J. Agric. Biol. Sci., 7: 255-270. DOI: 10.3844 /ajabssp.2012.255.270

Landi, M., L. Guidi, A. Pardossi, M. Tattini and K.S. Gould, 2014. Photoprotection by foliar anthocyanins mitigates effects of boron toxicity in sweet basil (Ocimum basilicum). Planta, 240: 941-953.

Landi, M., A. Pardossi, D. Remorini and L. Guidi, 2013. Antioxidant and photosynthetic response of a purple-leaved and a green-leaved cultivar of sweet basil (Ocimum basilicum L.) to boron excess. Environ. Exp. Bot., 85: 64-75.

Landi, M., M. Tattini and K.S. Gould, 2015. Multiple functional roles of anthocyanins in plantenvironment interactions. Environ. Exp. Bot., 119: 4-17.
Lobell, D.B. and C.B. Field, 2007. Global scale climatecrop yield relationships and the impacts of recent warming. Environ. Res. Lett., 2: 014002-014002. DOI:10.1088/1748-9326/2/1/014002

Naqqash, M.N., A. Gökçe, A. Bakhsh and M. Salim, 2016. Insecticide resistance and its molecular basis in urban insect pests. Parasitol Res. DOI: $10.1007 / \mathrm{s} 00436-015-4898-9$.

Pardossi, A., M. Romani, G. Carmassi, L. Guidi and M. Landi et al., 2015. Boron accumulation and tolerance in sweet basil (Ocimum basilicum L.) with green or purple leaves. Plant Soil, 395: 375-389.

Penella, C., M. Landi, L. Guidi, S.G. Nebauer and E. Pellegrini et al., 2016. Salt-tolerant rootstock increase yeld of pepper under salinity through maintenance of photosynthetic performances and sink strength. J. Plant Physiol., 193: 1-11.

Rasmussen, P.E., K.W.T Goulding, J.R. Brown, P.R. Grace and H.H. Janzen et al., 1998. Agroecosystem-longterm agroecosystem experiments: Assessing agricultural sustainability and global change. Science, 282: 893-896.

DOI: $10.1126 /$ science.282.5390.893

Sgroi, F., A.M. Di Trapani, R. Testa and S. Tudisca, 2014. Economic sustainability of early potato production in the Mediterranean area. Am. J. Appl. Sci., 11: 1598-1603.

DOI: 10.3844/ajassp.2014.1598.1603

Tattini, M., M. Landi, C. Brunetti, D. Remorini and K.S. Gould et al., 2014. Epidermal coumaroyl anthocyanins protect sweet basil against excess light stress: Multiple consequences of light attenuation. Physiol. Plantarum, 152: 585-598.

Testa, R., M. Foderà, A.M. Di Trapani, S. Tudisca and F. Sgroi, 2015. Choice between alternative investments in agriculture: The role of organic farming to avoid the abandonment of rural areas. Ecol. Eng., 83: 227-232.

Tubiello, F.N., M. Salvatore, R.D. Cóndor Golec, A. Ferrara and S. Rossi et al., 2014. Agriculture, forestry and other land use emissions by sources and removals by sinks. FAO report, EES/14-02 Working Paper No. $\quad 2$ http://www.fao.org/docrep/019/i3671e/i3671e.pdf

UNR, 2014. United Nations report. http://www.un.org/esa/population/publications/sixbi llion/sixbilpart1.pdf

U.S Census Bureau. http://www.census.gov/population/international/ 